\title{
Three minutes propofol after sevoflurane anesthesia to prevent emergence agitation following inguinal hernia repair in children: a randomized controlled trial
}

\author{
Mostafa Samy Abbas, Essam Ezzat Abd El-Hakeem, and \\ Hossam Esmat Kamel \\ Department of Anesthesia and Intensive Care Medicine, Assiut University Faculty of Medicine, Assiut, Egypt
}

\begin{abstract}
Background: Emergence agitation (EA) is a common problem after sevoflurane anesthesia among children. There have been mixed results with control of EA using propofol $1 \mathrm{mg} / \mathrm{kg}$ bolus following sevoflurane anesthesia. An infusion of 3 $\mathrm{mg} / \mathrm{kg}$ of propofol over $3 \mathrm{~min}$ following sevoflurane anesthesia has been found to be promising in children undergoing magnetic resonance imaging scans. However, no studies have been conducted during surgical procedures. We aimed to examine the efficacy of transition to propofol for $3 \mathrm{~min}$ after cessation of sevoflurane anesthesia in children undergoing inguinal hernia repair.

Methods: In this prospective randomized controlled trial, 64 children aged 1-12 years, scheduled for inguinal hernia repair, were randomized to receive either propofol $3 \mathrm{mg} / \mathrm{kg}$ over $3 \mathrm{~min}$ (propofol group) or no propofol (control group), after the cessation of sevoflurane anesthesia. EA was assessed using the Paediatric Emergence Anesthesia Delirium (PAED) scale and the Watcha scale. Emergence time and the duration of post-anesthesia care unit (PACU) stay were also recorded.

Results: The incidence of ED was lower in the propofol group on both the PAED ( $81.3 \%$ vs. $15.6 \%, \mathrm{P}<0.001)$ and the Watcha $(78.1 \%$ vs. $15.6 \%, \mathrm{P}<0.001)$ scales. The mean emergence time was 6.37 minutes longer in the propofol group with no significant difference in PACU times.

Conclusions: Transition to propofol $3 \mathrm{mg} / \mathrm{kg}$ over $3 \mathrm{~min}$ following sevoflurane anesthesia reduces the incidence of EA and improves the quality of emergence. Although emergence times were longer, the duration of stay in the PACU was similar with propofol use.
\end{abstract}

Keywords: Agitation; Delirium; Emergence; Pediatrics; Propofol; Sevoflurane.

Corresponding author: Mostafa Samy Abbas, M.D.

Department of Anesthesia and Intensive Care Medicine, Assiut University Faculty of Medicine, Assiut 71515, Egypt

Tel: 20-1003060187, Fax: 2088-2335520

Email: mostafasamy@aun.edu.eg

ORCID: https://orcid.org/0000-0003-2690-3294

Received: December 5, 2018.

Revised: January 24, 2019.

Accepted: February 21, 2019.

Korean J Anesthesiol 2019 June 72(3): 253-259

https://doi.org/10.4097/kja.d.18.00345

\section{Introduction}

In young children, anesthesia with sevoflurane has been shown to be accompanied by behavioral changes during recovery known as emergence agitation (EA) or emergence delirium (ED) $[1,2]$. EA is characterized by a period of restlessness, agitation, inconsolable crying, disorientation, delusions, and hallucinations with impaired cognition and memory [3].

$\mathrm{ED}$ is sometimes defined as a type of EA occurring in a few

(c) This is an open-access article distributed under the terms of the Creative Commons Attribution Non-Commercial License (http://creativecommons.org/ licenses/by-nc/4.0/), which permits unrestricted non-commercial use, distribution, and reproduction in any medium, provided the original work is properly cited. 
patients who experience delirium with psychomotor agitation $[1,2]$. The incidence of EA after sevoflurane anesthesia in children is reported to vary between $10 \%-80 \%$. This depends on the definition of EA used and the duration of monitoring after emergence from anesthesia [4]. Sevoflurane and desflurane anesthesia have been shown to be risk factors for EA in children. However, the precise etiology is still unclear $[4,5]$.

Many pharmacological interventions including propofol can minimize the incidence of EA following sevoflurane anesthesia [6-8]. A continuous infusion of propofol has been used throughout the procedure to reduce the incidence of EA in some studies [6,7]. A single bolus dose of $1 \mathrm{mg} / \mathrm{kg}$ of propofol has also been used with contrasting results [8-11]. Transition to propofol after sevoflurane anesthesia by repeated bolus administration has also been used to reduce EA [12]. An infusion of $3 \mathrm{mg} / \mathrm{kg}$ of propofol over $3 \mathrm{~min}$ following sevoflurane anesthesia has been found to be promising in children undergoing magnetic resonance imaging scans [13].

In this randomized trial, we aimed to determine whether transition to propofol over $3 \mathrm{~min}$ after cessation of sevoflurane anesthesia would reduce the incidence of EA in children undergoing inguinal hernia repair.

\section{Materials and Methods}

This prospective, single-blinded, randomized controlled trial was registered at www.clinicaltrials.gov (NCT03179293). The study was carried out at the Assiut University Paediatric Hospital, Egypt, between July 2017 to June 2018. The study protocol was approved by the Assiut Medical School Ethical Review Board (Ethical Committee N: IRB 17100561). Written informed consent was obtained from parents of all patients before inclusion in the study.

Children aged 1-12 years, American Society of Anesthesiology class I or II, assigned for elective inguinal hernia repair were included in the study. Exclusion criteria were patient or parent refusal, known allergy to propofol or egg products, a family history of malignant hyperthermia, operating time longer than 60 minutes, performance of any other procedure under the same anesthetic, other co-morbidities or congenital anomalies, neurological or psychiatric illness, use of sedatives, or the need for rapid sequence induction.

\section{Blinding and randomization}

Randomization was performed prior to the commencement of surgery using a computerized randomization system to ensure adequate allocation concealment. A study coordinator assigned patients either to the propofol group (propofol, $3 \mathrm{mg} / \mathrm{kg}$ intravenously, administered over $3 \mathrm{~min}$ after cessation of sevoflurane anesthesia) or the control group and were allocated random numbers. Outcomes were monitored by a researcher who was blinded to group allocation until the study was completed and the random code revealed. All procedures were carried out by one of two surgeons.

\section{Intervention}

Anesthesia was induced using sevoflurane and oxygen. Intravenous access was secured after induction. Anesthesia was maintained using sevoflurane and spontaneous ventilation was allowed through a laryngeal mask airway (LMA). A caudal epidural block was performed using $0.5 \mathrm{ml} / \mathrm{kg}$ of $0.25 \%$ bupivacaine after induction of anesthesia and paracetamol $15 \mathrm{mg} /$ $\mathrm{kg}$ intravenously was administered for supplemental analgesia. Patients randomized to the propofol group received propofol 3 $\mathrm{mg} / \mathrm{kg}$ intravenously over 3 minutes after cessation of sevoflurane anesthesia in the following manner: sevoflurane administration was ceased after completion of the procedure. An initial bolus of propofol $1 \mathrm{mg} / \mathrm{kg}$ was administered intravenously followed by $2 \mathrm{mg} / \mathrm{kg}$ given over the next $3 \mathrm{~min}$ before transferring the patient to the post-anesthesia care unit (PACU). The intravenous cannula was flushed with normal saline. Children in the control group did not receive propofol. The LMA was removed in all patients under deep anesthesia in the operating room and an oropharyngeal airway was inserted if airway obstruction was encountered. All patients received oxygen through a face mask until emergence and were monitored with pulse oximetry throughout their stay in the PACU.

\section{Study outcomes}

The primary outcome was the incidence of EA according to the Paediatric Emergence Anaesthesia Delirium (PAED) [3] and Watcha scales [13], recorded simultaneously at 5-minute intervals until 30 minutes after emergence. EA on the PAED scale was defined as a PAED score $>12$ throughout the first 30 minutes after emergence [1]. EA was diagnosed by a score of $\geq$ 3 on the Watcha scale at any point during the first 30 minutes after emergence. The secondary outcomes included peak PAED scores, emergence time, and the time spent in PACU. A blinded researcher monitored the patient from the time of arrival in the PACU until 30 minutes after emergence. The time to emergence was defined as the duration of time from the termination of anesthesia until the onset of eye-opening or purposeful movement.

\section{Statistical analysis}

Statistical analysis was performed using IBM SPSS Statistics for Windows (version 20.0, IBM Corp., USA). Data were pre- 


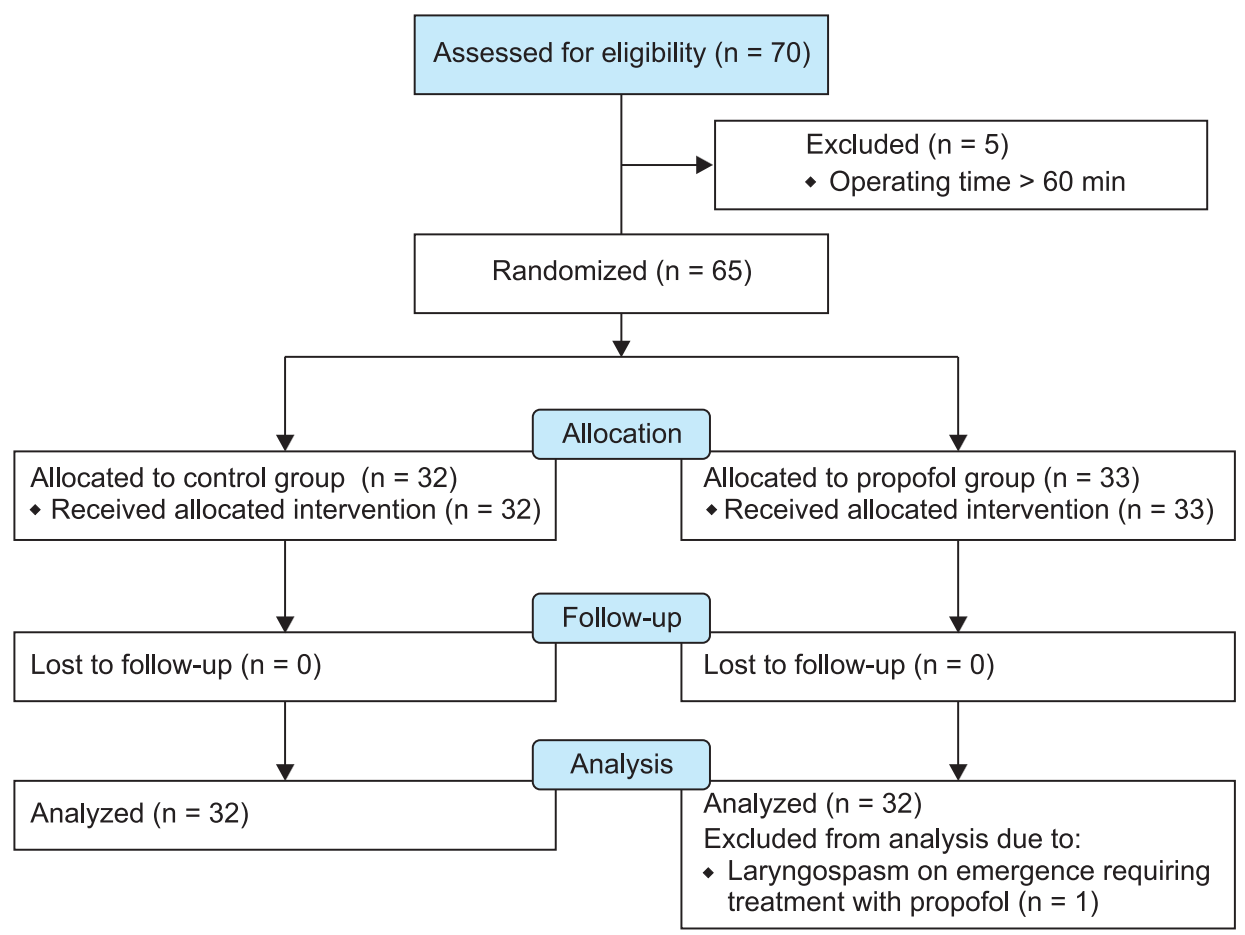

Fig. 1. CONSORT flow diagram.

sented as mean, $\mathrm{SD}$, range, numbers, and percentage. Demographic data and comparison between continuous variables were carried out using the Mann-Whitney $U$ test for non-normally distributed data and the Student's $t$-test for normally distributed data. The incidence of EA and comparison between categorical data were presented as frequency and percentage, using the chisquare test. A P value of $<0.05$ was considered as statistically significant.

\section{Sample size calculation}

We calculated the sample size based on a previous study that revealed a $50 \%$ incidence of EA in the control group [9]. Assuming a reduction in the incidence of EA by $15 \%$, we calculated the required sample size as 32 per group based on a power of $80 \%$ and a CI of $95 \%$. Allowing for possible dropouts, we recruited a total of 70 patients.

\section{Results}

We assessed 70 children for eligibility. Five patients were excluded as the duration of surgery was $>60 \mathrm{~min}$. The remaining 65 children were allocated into two groups. One patient was excluded from the final analysis due to laryngospasm requiring treatment (Fig. 1). Baseline characteristics were comparable in both groups (Table 1).

The overall incidence of EA according to the PEAD scale was $15.6 \%$ in the propofol group and $81.3 \%$ in the control group $(\mathrm{P}<$
Table 1. Demographic Characteristics of Study Participants

\begin{tabular}{lccc}
\hline & $\begin{array}{c}\text { Control } \\
\text { group }(\mathrm{n}=32)\end{array}$ & $\begin{array}{c}\text { Propofol } \\
\text { group }(\mathrm{n}=32)\end{array}$ & P value \\
\hline Sex (M/F) & $27 / 5$ & $29 / 3$ & 0.45 \\
Age (yr) & $4.5 \pm 1.7$ & $4.6 \pm 1.4$ & 0.84 \\
Weight (kg) & $17.1 \pm 4.5$ & $16.8 \pm 3.5$ & 0.81 \\
Anesthetic duration (min) & $35.0 \pm 11.8$ & $36.2 \pm 13.3$ & 0.69 \\
\hline
\end{tabular}

Values are presented as number of patient or mean \pm SD.

0.001). According to the Watcha scale, the incidence of EA was $15.6 \%$ in the propofol group and $78.13 \%$ in the control group (P $<0.001$ ) (Table 2).

Peak PAED scores were also significantly lower in the propofol group $(\mathrm{P}<0.001)$. The emergence times were significantly longer in the propofol group $(\mathrm{P}<0.001)$; however, there was no significant difference in the duration of stay in the PACU between groups.

Fig. 2 depicts peak PAED scores with lower PAED scores in the propofol group (median score $=9$ ) than the control group (median score $=16$ ) during stay in the PACU.

Figs. 3 and 4 represent the percentage of children who experienced EA (PAED score $>12$, Watcha score $\geq 3$ ) during the first 30 minutes after emergence. In contrast to the control group, no patient in the propofol group experienced EA beyond 15 minutes of emergence. 
Table 2. Emergence Agitation and Emergence Time

\begin{tabular}{|c|c|c|c|c|}
\hline & Control group & Propofol group & $P$ value & Risk ratio $(95 \% \mathrm{CI})$ \\
\hline \multicolumn{5}{|c|}{ Emergence agitation (all patients) } \\
\hline Using the PAED scale & $26 / 32(81.3 \%)$ & $5 / 32(15.6 \%)$ & $<0.001$ & $0.19(0.1-0.4)$ \\
\hline Using the Watcha scale & $25 / 32(78.1 \%)$ & $5 / 32(15.6 \%)$ & $<0.001$ & $0.20(0.1-0.5)$ \\
\hline Peak PAED scores & $16(14,17)$ & $9(8,11)$ & $<0.001$ & \\
\hline Emergence time (min) & $7.1 \pm 2.0$ & $13.4 \pm 2.5$ & $<0.001$ & \\
\hline Time in PACU (min) & $44.5 \pm 5.9$ & $46.6 \pm 7.6$ & 0.221 & \\
\hline
\end{tabular}

Values are presented as number (\%), median (IQR) or mean \pm SD. PAED: Pediatric Anesthesia Emergence Delirium, IQR: interquartile range, PACU: post-anesthesia care unit.
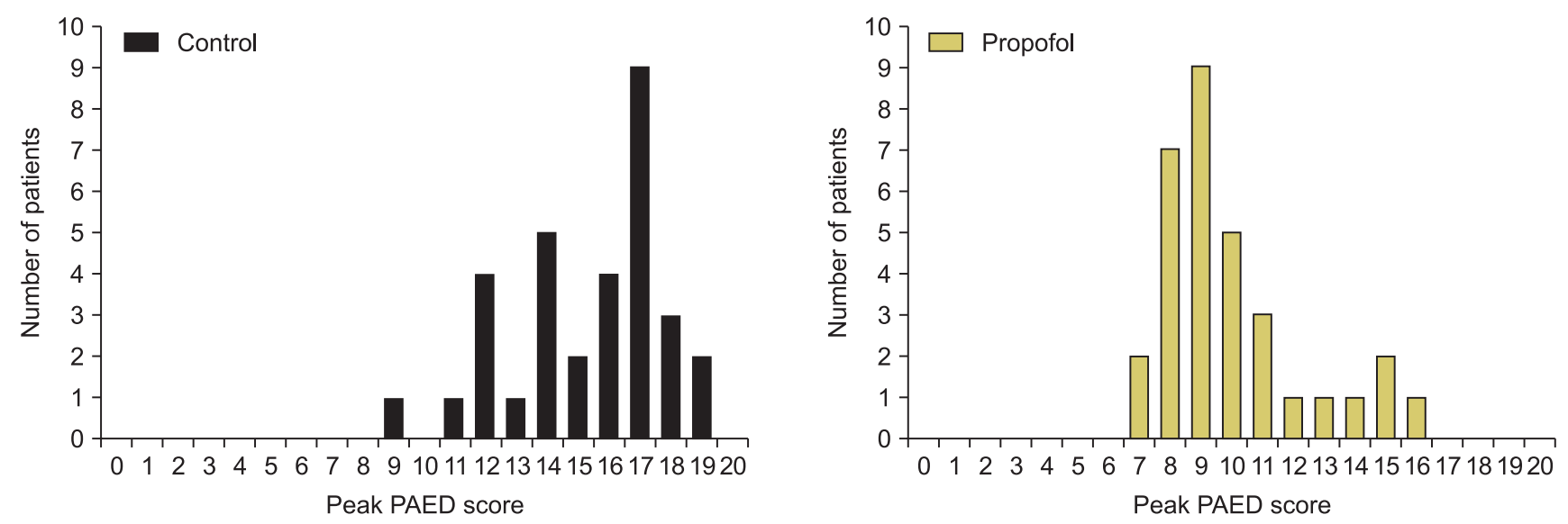

Fig. 2. Peak PAED scores in the first 30 min after emergence from anesthesia. PAED: Pediatric Anesthesia Emergence Delirium.

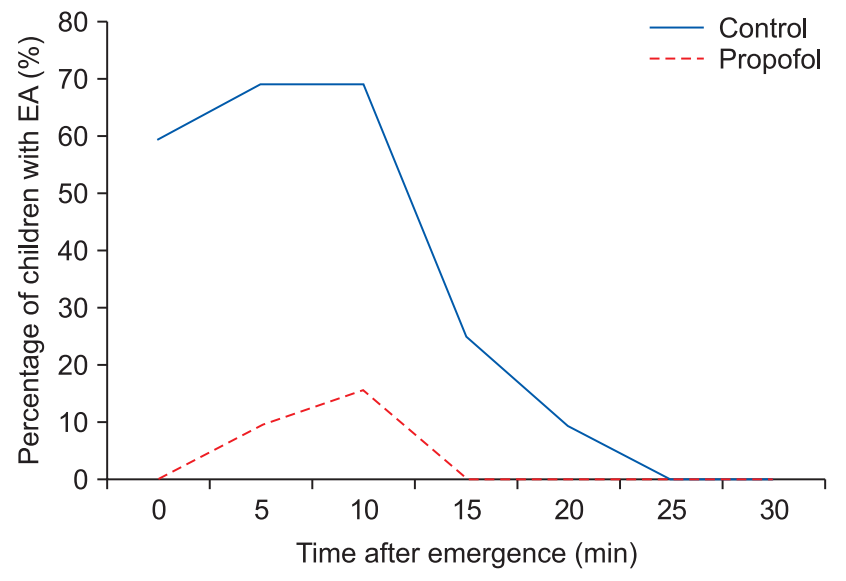

Fig. 3. Proportion of children with emergence agitation (PAED score > 12) against time after emergence. PAED: Pediatric Anesthesia Emergence Delirium, EA: emergence agitation.

\section{Discussion}

In the present study, the simple transition to an infusion of propofol $3 \mathrm{mg} / \mathrm{kg}$ for 3 minutes following the cessation of sevoflurane anesthesia was associated with a significant decrease in

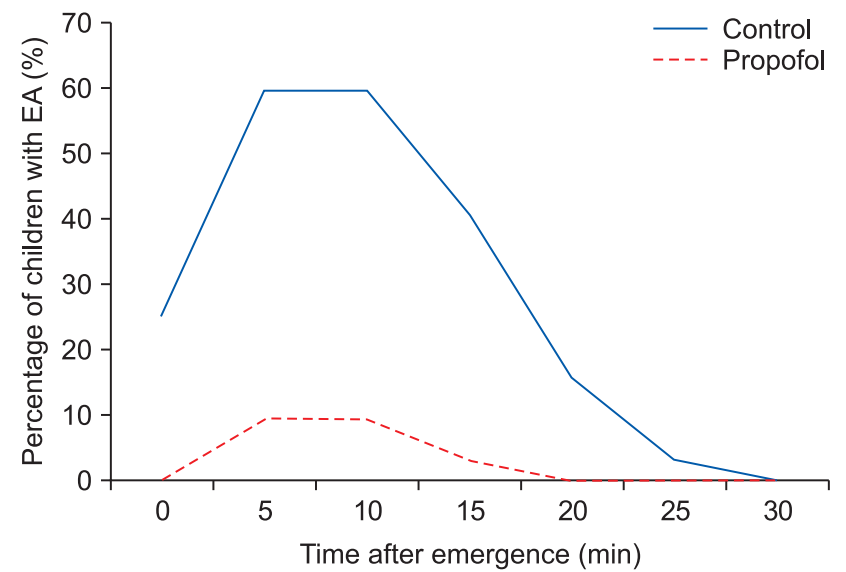

Fig. 4. Proportion of children with emergence agitation (Watcha score $\geq$ 3) against time after emergence.

the incidence, severity, and duration of EA.

The etiology of EA is not clearly understood. Yasui et al. [14] described an increase in noradrenaline release following sevoflurane exposure in the preoptic area of the brain in rats, especially in the locus coeruleus. It has been suggested that this leads to disorientation in the early stages of recovery, resulting 
in the agitation component of EA. EA may also occur due to rapid elimination of inhalational agents including sevoflurane, desflurane, and isoflurane [15] or due to postoperative pain [16]; transition to propofol may offset this effect and prevent EA.

Many clinical studies have shown that EA following sevoflurane anesthesia in children is a widespread problem and is significantly higher than with other inhalational anesthetics or propofol-based anesthesia [17-23]. Some studies have shown that the incidence of EA after total intravenous anesthesia with propofol ranges from $0 \%-9 \%$ compared to $23 \%-46 \%$ after sevoflurane anesthesia $[19,20,24]$. However, this technique is more complicated with the requirement for infusion pumps and complex dose adjustment.

In a previous report, propofol $2 \mathrm{mg} / \mathrm{kg}$ was administered at the beginning of surgery during sevoflurane anesthesia to reduce the incidence of EA. However, no decrease in the incidence of EA was observed with this technique [25]. A bolus dose of $1 \mathrm{mg} /$ $\mathrm{kg}$ of propofol was administered at the completion of surgery to prevent EA, with contrasting results. Five studies showed benefit $[8,9,26-28]$ with this technique while three studies showed no effect $[10,11,29]$.

A preliminary trial with propofol $3 \mathrm{mg} / \mathrm{kg}$ administered over 3 minutes after cessation of sevoflurane anesthesia revealed a decrease in the incidence of EA according to the PAED and Watcha scales. However, this study was performed in children undergoing magnetic resonance imaging scan [30]. To our knowledge, ours is the only study that investigated the simple technique of transition to $3 \mathrm{mg} / \mathrm{kg}$ propofol administered over 3 minutes after cessation of sevoflurane anesthesia in an operative setting with associated stress factors.

Our study showed a significant decrease in the incidence of EA after sevoflurane anesthesia in the propofol group compared to control subjects. Overall, a decrease in the agitation scores was observed with propofol administration. This implies a decrease in the severity of EA with improvement in the quality of emergence leading to improved parental and staff satisfaction. Despite the significant increase in emergence times, there was no significant increase in the duration of PACU stay. Hence, the statistically significant decrease in EA also resulted in improved clinical outcomes. The delay in emergence in our study would suggest that the mechanism of action of transitioning to propofol may be the facilitation of sevoflurane washout prior to the point of emergence.

Our study has several limitations. First, we did not assess the safety of propofol use including airway complications and apnea. Second, the study subjects underwent inguinal hernia repair under caudal epidural analgesia combined with intravenous paracetamol; hence our results may not be generalizable to other surgical settings. Our results need to be validated in different surgical settings.
Another limitation of our study is the use of the PAED scale to detect EA. Sikich and Lerman [3] who devised this scale did not define a cut-off point that denotes the presence of EA. Cutoff scores $\geq 10$ and $\geq 16$ have been studied without strong justification for the scale used [1]. Aouad et al. [9] studied 80 children aged between 2-6 years who underwent strabismus surgery under sevoflurane anesthesia. A PAED score of 10 or less was considered acceptable in their study. Patients who were administered propofol $1 \mathrm{mg} / \mathrm{kg}$ intravenously at the end of surgery had a $19.5 \%$ incidence of EA compared to $47.2 \%$ in the placebo group. While the intervention group in this study experienced a significantly lower incidence of EA, the effect was less than optimal. The time to recovery was also longer in the propofol group compared to the control group. When a PAED score of 16 was considered acceptable, Abu-Shahwan [8] noticed a $4.8 \%$ incidence of EA with propofol $1 \mathrm{mg} / \mathrm{kg}$ compared to $26.8 \%$ in the control group. We speculate that acceptance of a higher PAED score in this study may have resulted in a significantly better outcome compared to the study by Aouad et al. The aforementioned studies using propofol $[8,9]$ documented a high incidence of EA using a cut off of 10 points on the PAED score; the incidence was much lower using a cut off of 16 points. Clearly, a different approach towards the assessment of EA needs to be evaluated. In the present study, using a cut off of 12 on the PEAD scale and 3 on the Watcha scale for the assessment of EA after transition to propofol $3 \mathrm{mg} / \mathrm{kg}$, we observed a lower incidence of EA in the propofol group ( $81.3 \%$ vs. $15.6 \%, \mathrm{P}<0.001$ using the PAED scale and $78.1 \%$ vs. $15.6 \%, \mathrm{P}<0.001$ using the Watcha scale). We used the Watcha scale in addition to the PAED scale because it is much simpler and easy to measure and may increase overall accuracy of assessment.

In conclusion, the transition to propofol $3 \mathrm{mg} / \mathrm{kg}$ for $3 \mathrm{~min}$ utes following sevoflurane anesthesia significantly decreased the incidence, severity, and duration of EA. Although there was an increase in emergence times, there was no increase in the duration of PACU stay after surgery.

\section{Conflicts of Interest}

No potential conflict of interest relevant to this article was reported.

\section{Author Contributions}

Mostafa Samy Abbas (Methodology; Writing - original draft) Esam Ezzat Abd El-Hakeem (Conceptualization; Data curation; Formal analysis; Methodology; Supervision; Validation; Writing - review \& editing)

Hosam Esmat Kamel (Conceptualization; Data curation; Formal analysis; Investigation; Methodology; Validation; Visualization; 
Writing - original draft; Writing - review \& editing)

\section{ORCID}

Mostafa Samy Abbas, https://orcid.org/0000-0003-2690-3294

Essam Ezzat Abd El-Hakeem, https://orcid.org/0000-0002-4502-

3201

Hossam Esmat Kamel, https://orcid.org/0000-0002-5916-9332

\section{References}

1. Bajwa SA, Costi D, Cyna AM. A comparison of emergence delirium scales following general anesthesia in children. Paediatr Anaesth 2010; 20: 704-11.

2. Malarbi S, Stargatt R, Howard K, Davidson A. Characterizing the behavior of children emerging with delirium from general anesthesia. Paediatr Anaesth 2011; 21: 942-50.

3. Sikich N, Lerman J. Development and psychometric evaluation of the pediatric anesthesia emergence delirium scale. Anesthesiology 2004; 100: 1138-45.

4. Vlajkovic GP, Sindjelic RP. Emergence delirium in children: many questions, few answers. Anesth Analg 2007; 104: 84-91.

5. Voepel-Lewis T, Malviya S, Tait AR. A prospective cohort study of emergence agitation in the pediatric postanesthesia care unit. Anesth Analg 2003; 96: 1625-30.

6. Costi D, Cyna AM, Ahmed S, Stephens K, Strickland P, Ellwood J, et al. Effects of sevoflurane versus other general anaesthesia on emergence agitation in children. Cochrane Database Syst Rev 2014; (9): CD007084.

7. Dahmani S, Stany I, Brasher C, Lejeune C, Bruneau B, Wood C, et al. Pharmacological prevention of sevoflurane- and desflurane-related emergence agitation in children: a meta-analysis of published studies. Br J Anaesth 2010; 104: 216-23.

8. Abu-Shahwan I. Effect of propofol on emergence behavior in children after sevoflurane general anesthesia. Paediatr Anaesth 2008; $18: 55-9$.

9. Aouad MT, Yazbeck-Karam VG, Nasr VG, El-Khatib MF, Kanazi GE, Bleik JH. A single dose of propofol at the end of surgery for the prevention of emergence agitation in children undergoing strabismus surgery during sevoflurane anesthesia. Anesthesiology 2007; 107: 7338.

10. Bakhamees HS, Mercan A, El-Halafawy YM. Combination effect of low dose fentanyl and propofol on emergence agitation in children following sevoflurane anesthesia. Saudi Med J 2009; 30: 500-3.

11. Lee CJ, Lee SE, Oh MK, Shin CM, Kim YJ, Choe YK, et al. The effect of propofol on emergence agitation in children receiving sevoflurane for adenotonsillectomy. Korean J Anesthesiol 2010; 59: 75-81.

12. Fronapfel PJ. Prevention of emergence delirium. Paediatr Anaesth 2008; 18: 1113-4.

13. Watcha MF, Ramirez-Ruiz M, White PF, Jones MB, Lagueruela RG, Terkonda RP. Perioperative effects of oral ketorolac and acetaminophen in children undergoing bilateral myringotomy. Can J Anaesth 1992; 39: 649-54.

14. Yasui Y, Masaki E, Kato F. Sevoflurane directly excites locus coeruleus neurons of rats. Anesthesiology 2007; 107: 992-1002.

15. Lerman J, Davis PJ, Welborn LG, Orr RJ, Rabb M, Carpenter R, et al. Induction, recovery, and safety characteristics of sevoflurane in children undergoing ambulatory surgery. A comparison with halothane. Anesthesiology 1996; 84: 1332-40.

16. Galinkin JL, Fazi LM, Cuy RM, Chiavacci RM, Kurth CD, Shah UK, et al. Use of intranasal fentanyl in children undergoing myringotomy and tube placement during halothane and sevoflurane anesthesia. Anesthesiology 2000; 93: 1378-83.

17. Welborn LG, Hannallah RS, Norden JM, Ruttimann UE, Callan CM. Comparison of emergence and recovery characteristics of sevoflurane, desflurane, and halothane in pediatric ambulatory patients. Anesth Analg 1996; 83: 917-20.

18. Johannesson GP, Florén M, Lindahl SG. Sevoflurane for ENT-surgery in children. A comparison with halothane. Acta Anaesthesiol Scand 1995; 39: 546-50.

19. Uezono S, Goto T, Terui K, Ichinose F, Ishguro Y, Nakata Y, et al. Emergence agitation after sevoflurane versus propofol in pediatric patients. Anesth Analg 2000; 91: 563-6.

20. Picard V, Dumont L, Pellegrini M. Quality of recovery in children: sevoflurane versus propofol. Acta Anaesthesiol Scand 2000; 44: 307-10.

21. Beskow A, Westrin P. Sevoflurane causes more postoperative agitation in children than does halothane. Acta Anaesthesiol Scand 1999; 43: 536-41.

22. Cravero J, Surgenor S, Whalen K. Emergence agitation in paediatric patients after sevoflurane anaesthesia and no surgery: a comparison with halothane. Paediatr Anaesth 2000; 10: 419-24.

23. Cravero JP, Beach M, Dodge CP, Whalen K. Emergence characteristics of sevoflurane compared to halothane in pediatric patients undergoing bilateral pressure equalization tube insertion. J Clin Anesth 2000; 12: 397-401.

24. Cohen IT, Finkel JC, Hannallah RS, Hummer KA, Patel KM. Rapid emergence does not explain agitation following sevoflurane anaesthesia in infants and children: a comparison with propofol. Paediatr Anaesth 2003; 13: 63-7.

25. Cohen IT, Drewsen S, Hannallah RS. Propofol or midazolam do not reduce the incidence of emergence agitation associated with desflurane 
anaesthesia in children undergoing adenotonsillectomy. Paediatr Anaesth 2002; 12: 604-9.

26. Sun Y, Wenyin XU, Jie HU, Wenyan XU, Bai J, Zhang M. Combination effect of tramadol and low dose propofol on emergence agitation in children receiving sevoflurane for adenotonsillectomy procedure. J Shanghai Jiaotong Univ (Med Sci) 2010; 30: 73-5.

27. Kim YH, Yoon SZ, Lim HJ, Yoon SM. Prophylactic use of midazolam or propofol at the end of surgery may reduce the incidence of emergence agitation after sevoflurane anaesthesia. Anaesth Intensive Care 2011; 39: 904-8.

28. Kim MS, Moon BE, Kim H, Lee JR. Comparison of propofol and fentanyl administered at the end of anaesthesia for prevention of emergence agitation after sevoflurane anaesthesia in children. Br J Anaesth 2013; 110: 274-80.

29. Chiba S, Shima T, Murakami N, Kato M. Effect of propofol on sevoflurane agitation in children. Masui 2003; 52: 611-5.

30. Costi D, Ellwood J, Wallace A, Ahmed S, Waring L, Cyna A. Transition to propofol after sevoflurane anesthesia to prevent emergence agitation: a randomized controlled trial. Paediatr Anaesth 2015; 25: 517-23. 